\title{
Feasibility Study on Chemical Flooding in Super High Porosity and Permeability Heavy Oil Reservoir
}

\author{
Juan Zhao',2, Jian Zhang1,2, Guang Yang ${ }^{1,2}$ \\ ${ }^{1}$ China State Key Lab of Offshore Oil Exploitation, Beijing, China \\ ${ }^{2}$ CNOOC Research Institute CO., Ltd., Beijing, China \\ Email: zhaojuanupc@163.com
}

How to cite this paper: Zhao, J., Zhang, J. and Yang, G. (2020) Feasibility Study on Chemical Flooding in Super High Porosity and Permeability Heavy Oil Reservoir. Journal of Materials Science and Chemical Engineering, 8, 43-53.

https://doi.org/10.4236/msce.2020.811004

Received: August 3, 2020

Accepted: November 22, 2020

Published: November 25, 2020

Copyright $\odot 2020$ by author(s) and Scientific Research Publishing Inc. This work is licensed under the Creative Commons Attribution International License (CC BY 4.0).

http://creativecommons.org/licenses/by/4.0/

\begin{abstract}
In this paper, the feasibility study of chemical flooding is carried out for ultra-high porosity and high permeability heavy oil field with permeability higher than $10 \mu \mathrm{m}^{2}$ and porosity greater than $35 \%$. The viscosity-concentration relationship of four kinds of oil flooding systems such as hydrolyzed polyacrylamide, structural polymer A, structural polymer B and gel was studied. The results showed that the viscosity of ordinary polymer and structural polymer B was lower compared with other two types of oil displacement agents, and the viscosity of structural polymer A was higher. The higher the concentration, the higher the viscosity retention rate. The gel system has the highest viscosity and best anti-shear ability. The resistance coefficient and residual resistance coefficient of structural polymer A and gel system were further studied. The results show that permeability, velocity and polymer concentration all affect the resistance coefficient and residual resistance coefficient. From the point of view of resistance establishment ability, it is considered that structural polymer $\mathrm{A}$ is not suitable for permeability formation above 10 $\mu \mathrm{m}^{2}$. Gel system has stronger ability to establish resistance coefficient than structural polymer A flooding system, and it is more feasible for formation system with permeability above $10 \mu \mathrm{m}^{2}$.
\end{abstract}

\section{Keywords}

Super High Porosity and High Permeability, Chemical Flooding,

Viscosity-Concentration Relationship, Resistance Coefficient, Coefficient of

Residual Resistance

\section{Introduction}

According to different permeabilities, reservoirs [1] [2] [3] can be divided into 
five types: super high permeability reservoir: air permeability of reservoir rock > $2000 \times 10^{-3} \mu \mathrm{m}^{2}$; high permeability reservoir: $500 \times 10^{-3} \mu \mathrm{m}^{2} \leq$ air permeability of reservoir rock $\leq 2000 \times 10^{-3} \mu \mathrm{m}^{2}$; medium permeability reservoir: $50 \times 10^{-3}$ $\mu \mathrm{m}^{2}$ air permeability of reservoir rock $<500 \times 10^{-3} \mu \mathrm{m}^{2}$; low permeability reservoir: air permeability of reservoir rock $<50 \times 10^{-3} \mu^{2}$. According to porosity, it is generally divided into ultra-high porosity reservoir (porosity $>30 \%$ ), high porosity reservoir (porosity $25 \%$ - 30\%), medium porosity reservoir (porosity $15 \%-25 \%$ ), low porosity (porosity $10 \%-15 \%$ ) and ultra-low porosity (porosity $<10 \%)$. Different types of reservoirs have different development methods [4] [5], for reservoirs with high permeability and serious heterogeneity, chemical flooding is often used. In low permeability reservoirs, fracturing measures can be adopted, and then water injection and gas injection can be used to supplement formation energy. Chemical flooding [6] [7] [8] technology has become an important means to greatly enhance oil recovery in medium and high permeability oilfields. Chemical flooding technology plays an important role in increasing production and stabilizing production in both onshore and offshore oilfields. The mechanism of polymer flooding [2] [3] [4] [5] is to improve the oil-water mobility ratio, effectively improve the sweep efficiency of displacement phase, reduce oil saturation, and achieve the improvement of oil recovery. Bohai oilfield belongs to offshore oilfield. Chemical flooding technology of high porosity and high permeability reservoir started in 2003. After more than ten years of development, it has formed a large scale and achieved good economic benefits. The research on adaptability of chemical flooding for ultra-high porosity and high permeability heavy oil fields with average permeability greater than $10 \mu \mathrm{m}^{2}$ can provide technical countermeasures for efficient development of such reservoirs; on the other hand, it is of great significance to expand the scope of chemical flooding in offshore oilfield and improve chemical flooding technology. In this paper, the viscosity, resistance coefficient and residual resistance coefficient of partially hydrolyzed polyacrylamide, structural polymer A [9], structural polymer B [10] and gel were studied, and the best system was selected out of four.

\section{Experimental Conditions and Methods}

\subsection{Experimental Conditions}

Experimental temperature: $50^{\circ} \mathrm{C}$.

Experimental water: the simulated water is prepared according to the ion composition of the mixed water in the oilfield at the present stage. The mineralization degree is $13,930 \mathrm{mg} / \mathrm{L}$. the ion composition is shown in Table 1 .

Experimental drug:

Table 1. Ion composition of simulated water in oil field.

\begin{tabular}{cccccccccc}
\hline $\begin{array}{c}\mathrm{Na}^{+} \\
(\mathrm{mg} / \mathrm{L})\end{array}$ & $\begin{array}{c}\mathrm{Cl}^{-} \\
(\mathrm{mg} / \mathrm{L})\end{array}$ & $\begin{array}{c}\mathrm{SO}_{4}^{2-} \\
(\mathrm{mg} / \mathrm{L})\end{array}$ & $\begin{array}{c}\mathrm{HCO}_{3}^{-} \\
(\mathrm{mg} / \mathrm{L})\end{array}$ & $\begin{array}{c}\mathrm{Na}^{+} \\
(\mathrm{mg} / \mathrm{L})\end{array}$ & $\begin{array}{c}\mathrm{Ca}^{2+} \\
(\mathrm{mg} / \mathrm{L})\end{array}$ & $\begin{array}{c}\mathrm{Mg}^{2+} \\
(\mathrm{mg} / \mathrm{L})\end{array}$ & $\begin{array}{c}\mathrm{K}^{+} \\
(\mathrm{mg} / \mathrm{L})\end{array}$ & $\begin{array}{c}\mathrm{Sr}^{2-} \\
(\mathrm{mg} / \mathrm{L})\end{array}$ & $\begin{array}{c}\mathrm{TDS} \\
(\mathrm{mg} / \mathrm{L})\end{array}$ \\
\hline 1934 & 5887 & 229 & 1609 & 4826.7 & 143 & 98 & 4023 & 4.7 & 13,930 \\
\hline
\end{tabular}


Partially hydrolyzed polyacrylamide (HPAM, industrial product, molecular weight of $1200 \times 10^{4} \mathrm{~g} / \mathrm{mol}$, hydrolysis degree $21.2 \%$ ), structural polymer A (solid content $91.22 \%$, molecular weight $1200 \times 10^{4} \mathrm{~g} / \mathrm{mol}$, hydrolysis $21.65 \%$ ), structural polymer $\mathrm{B}\left(\right.$ molecular weight $600 \times 10^{4} \mathrm{~g} / \mathrm{mol}$ ), gel (partially hydrolyzed polyacrylamide and phenolic resin crosslinking agent and auxiliaries) Gel system).

\subsection{Experimental Methods}

1) Viscosity concentration relationship before and after shearing

The simulated formation water was used to prepare different polymer mother liquor $(5000 \mathrm{mg} / \mathrm{L})$ and diluted to different polymer concentrations. The polymer was sheared with a warming agitator at a shear rate of $3000 \mathrm{r} / \mathrm{min}$ and a shearing time of $20 \mathrm{~s}$. The viscosity and viscosity retention rate of polymer solution before and after shear were measured, and the viscosity concentration relationship and viscosity retention curve before and after shear were drawn. The viscosity and concentration of all kinds of polymers and gels before and after shearing were determined.

The apparent viscosity retention was calculated according to the formula

$$
R_{v}=\frac{\eta_{t}}{\eta_{0}} \times 100 \%
$$

where,

$R_{V}$-apparent viscosity retention rate, expressed as a percentage;

$\eta_{0}, \eta_{t}$-apparent viscosity of polymer solution before and after stirring, unit: mPa.s.

2) Resistance coefficient and residual resistance coefficient

The resistance coefficient and the residual resistance coefficient are the technical indicators of the ability of the PPG system to improve mobility ratio and reduce reservoir permeability. The experimental device is shown in Figure 1, and the flow rate was $1 \mathrm{~mL} / \mathrm{min}$. Experimental steps are as follows:

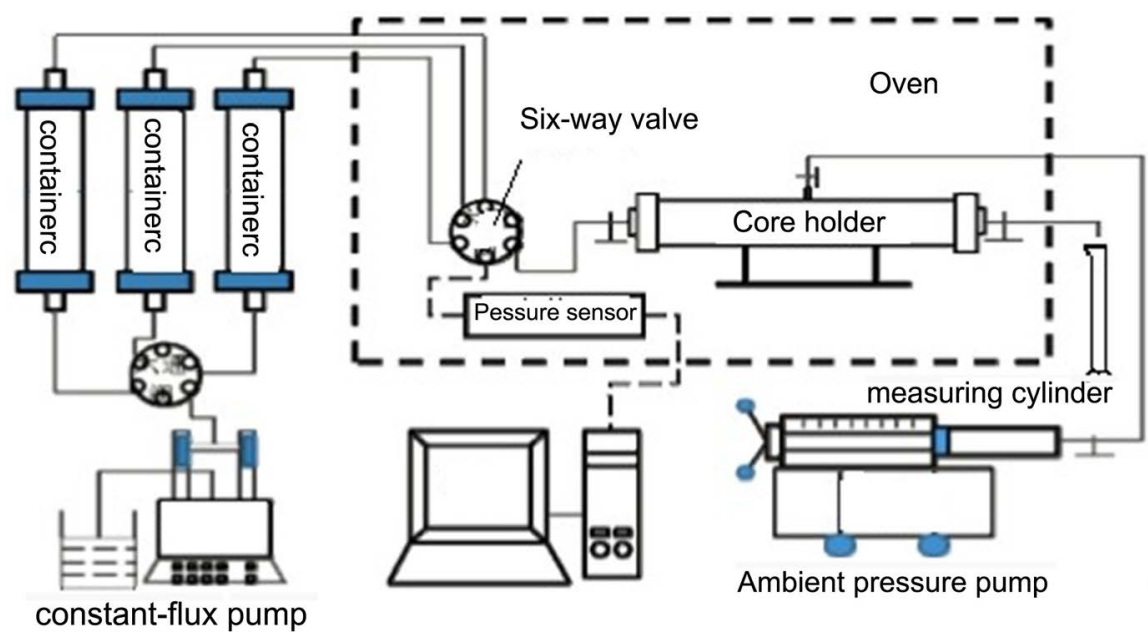

Figure 1. Schematic diagram of injection experimental device of profile control agent. 
a) All devices were connected according to Figure 1;

b) The simulated water and PPG solution was put into the middle containers respectively;

c) The incubator was preheat to the experimental temperature of $65^{\circ} \mathrm{C}$;

d) Water was injected into the sand pack at a constant flow rate until the pressure is stable, at which the pressure difference is $\Delta P_{w i}$;

e) PPG solution was injected with the same flow rate as the water injection until the pressure is stable, at which the pressure difference is $\Delta P_{w h}$;

f) The simulated water was injected with the same flow rate as the water injection until the pressure is stable, at which the pressure difference is $\Delta P_{w a}$.

The resistance coefficient is shown in formula (1) and the residual resistance coefficient is shown in formula (2):

$$
\begin{gathered}
F_{R}=\frac{\Delta P_{w h}}{\Delta P_{w i}} \\
F_{R R}=\frac{\Delta P_{w a}}{\Delta P_{w i}}
\end{gathered}
$$

where,

$F_{R}$-the resistance coefficient;

$F_{R R}$-the residual resistance coefficient;

$\Delta P_{w h}$-Pressure difference when the pressure of PPG solution is stable, $\mathrm{MPa}$;

$\Delta P_{w I}$-Pressure difference when the pressure of initial waterflooding is stable, $\mathrm{MPa}$;

$\Delta P_{w a}$-The pressure difference when the PPG solution is injected and the pressure of subsequent waterflooding is stable, MPa.

3) Oil displacement experiment with parallel sand pack

The parallel sand pack experiment reflects the heterogeneity of the formation and the profile adjustment of the system. The experimental process is as follows:

a) Connect all devices according to Figure 2;

b) Put the simulated water, simulated oil and chemical solution into the container in the middle respectively;

c) Preheat the incubator to the experimental temperature of $65^{\circ} \mathrm{C}$;

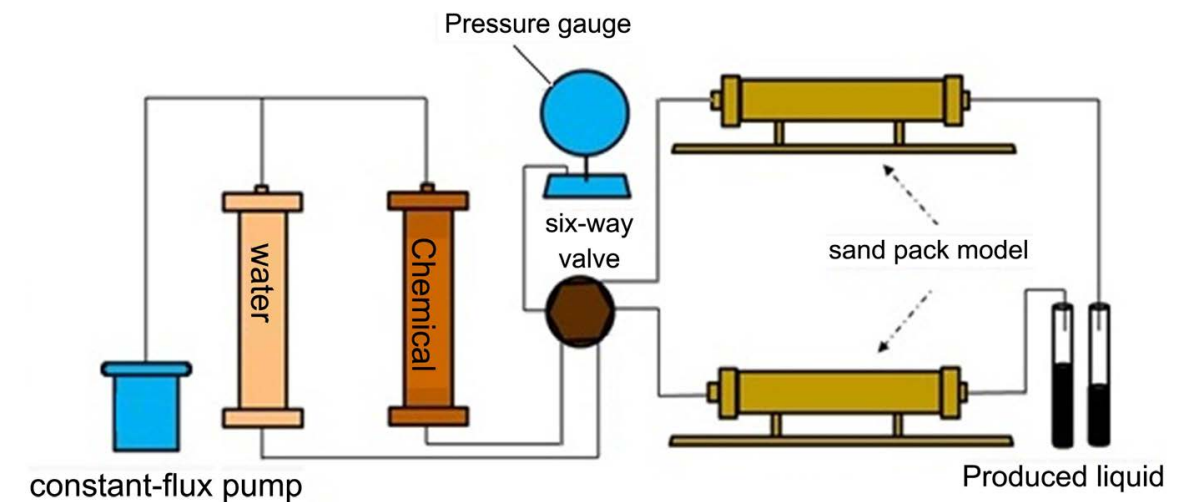

Figure 2. Schematic diagram of parallel sand-filling tube oil displacement device. 
d) The permeability of water phase in sand pack is calculated when the pressure is stable after injecting water in a constant flow rate;

e) Saturate the simulated oil at high temperature to prevent core damage or sand migration caused by too high viscosity of the simulated oil. The saturation temperature should be $10^{\circ} \mathrm{C}$ higher than the experimental temperature. Record the volume of displaced water, and that value is the saturated oil volume. (recording must be finished at experimental temperature, and the device must be sealed well to prevent loss caused by volatilization);

f) Aging sand pack: close the inlet and outlet and age for 72 hours at the experimental temperature;

g) Set water cut for water flooding;

h) Inject the chemical solution at same flow rate as water injection until the pressure is stable;

i) Inject the simulated water at same flow rate as water injection to the target water cut.

\section{Experimental Results}

\subsection{Viscosity Concentration Relation}

1) Partially hydrolyzed polyacrylamide

Dilute the mother liquor of partially hydrolyzed polyacrylamide to $1000 \mathrm{mg} / \mathrm{L}$, $2000 \mathrm{mg} / \mathrm{L}, 3000 \mathrm{mg} / \mathrm{L}$ and $4000 \mathrm{mg} / \mathrm{L}$, and shear with Wuyin stirrer. Determine the viscosity after shearing, viscosity concentration relationship and viscosity retention rate are shown in Figure 3.

2) structural polymer $A$

The mother liquor of structural polymer A was diluted to $1000 \mathrm{mg} / \mathrm{L}, 2000$ $\mathrm{mg} / \mathrm{L}, 3000 \mathrm{mg} / \mathrm{L}$ and $4000 \mathrm{mg} / \mathrm{L}$. the shear viscosity was determined by Wu Yin agitator. The viscosity concentration relationship and viscosity retention rate were shown in Figure 4.

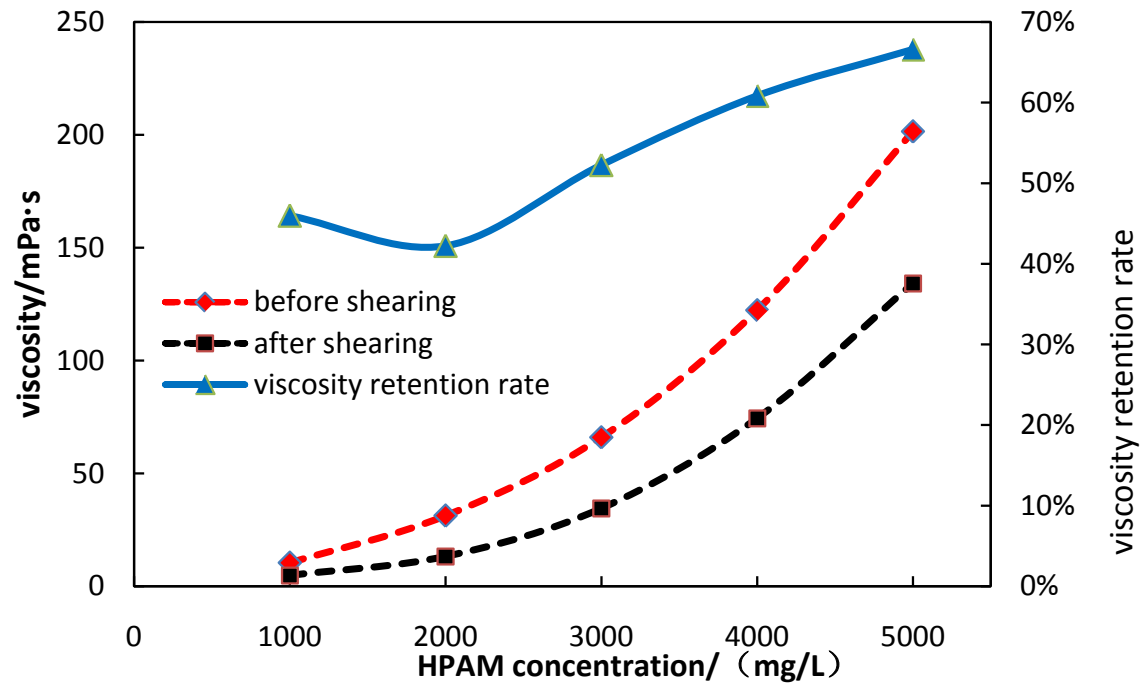

Figure 3. Viscosity concentration curve of HPAM before and after shearing. 


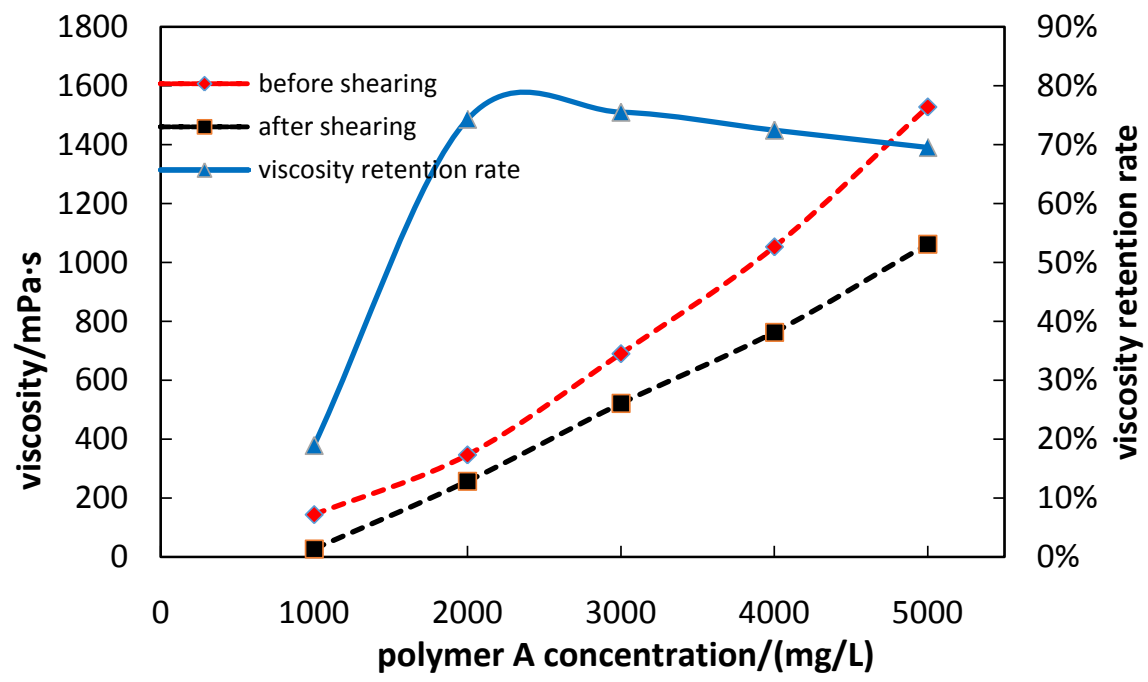

Figure 4. Viscosity concentration curve of polymer A before and after shearing.

3) structural polymer B

Dilute the mother liquor of structural polymer B to $1000 \mathrm{mg} / \mathrm{L}, 2000 \mathrm{mg} / \mathrm{L}$, $3000 \mathrm{mg} / \mathrm{L}, 4000 \mathrm{mg} / \mathrm{L}$, and shear with Wuyin agitator. Determine the viscosity after shearing. See Figure 5 for viscosity concentration relationship and viscosity retention rate.

4) gel

Gel composition: $1000 \mathrm{mg} / \mathrm{L}$ - $3000 \mathrm{mg} / \mathrm{L}$ structural polymer A +0.15\% main crosslinking agent +0.15 cross linking agent, main crosslinking agent and auxiliary crosslinking agent concentration unchanged, changing polymer viscosity. Crosslinking time: $30 \mathrm{~h}$, crosslinking temperature: $50^{\circ} \mathrm{C}$. As the concentration of the main crosslinking agent and the crosslinking agent is unchanged, the consistency of the gel before and after shearing is shown in Figure 6 with the polymer concentration as the abscissa.

Gel stability is an important property that restricts its application. Static gel aging for 15 days at different concentrations of $50^{\circ} \mathrm{C}$ is shown in Table 2. From Table 2, it is known that gel $2000 \mathrm{mg} / \mathrm{L}$ has higher viscosity and higher shear retention rate after gelation. When polymer concentration is $3000 \mathrm{mg} / \mathrm{L}$, long time static will lead to gel dehydration, so the polymer concentration in gel formula is $2000-2500 \mathrm{mg} / \mathrm{L}$, and the performance is better.

The data in Figures 2-5 are summarized to get Table 3. Table 3 shows that the viscosity of ordinary polymer and structural polymer B is lower before and after shearing. The viscosity of structural polymer A is higher before and after shearing. The higher the concentration, the higher the viscosity retention rate, the highest viscosity of the gel system, and the best shear resistance. and gel were used to carry out the experiment of drag coefficient and residual resistance coefficient.

\subsection{Resistance Coefficient and Residual Resistance Coefficient}

The porosity of sand filling pipe with permeability of $10 \mu \mathrm{m}^{2}$ and $20 \mu \mathrm{M}^{2}$ is 


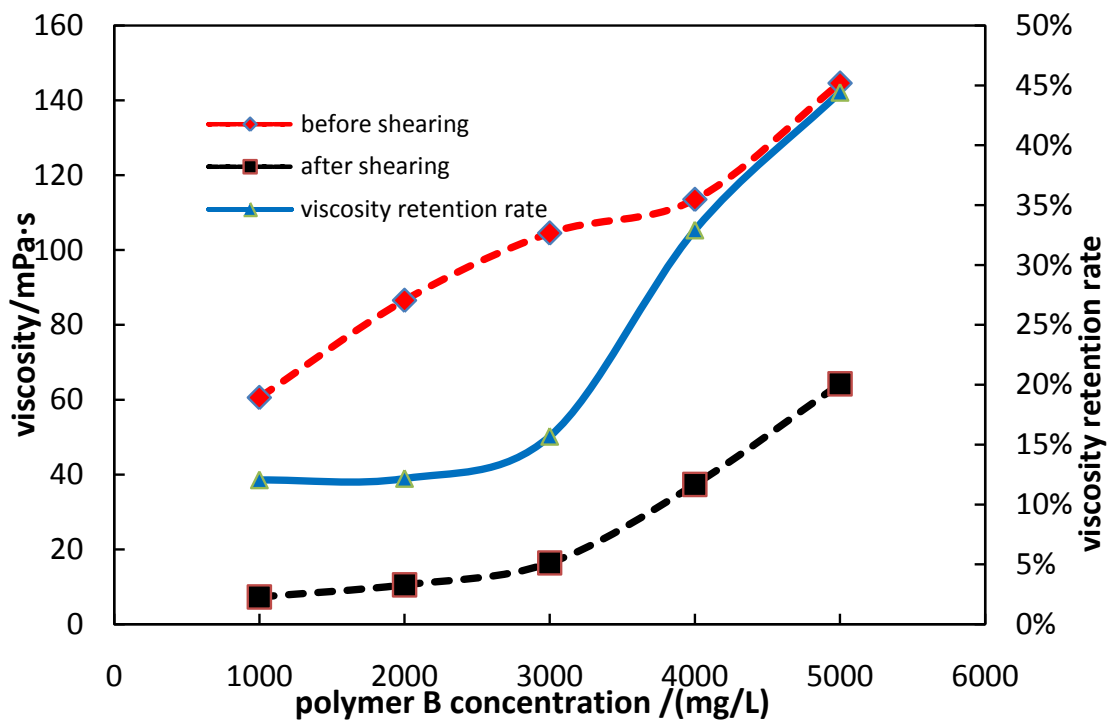

Figure 5. Viscosity concentration curve of structural polymer B before and after shearing.

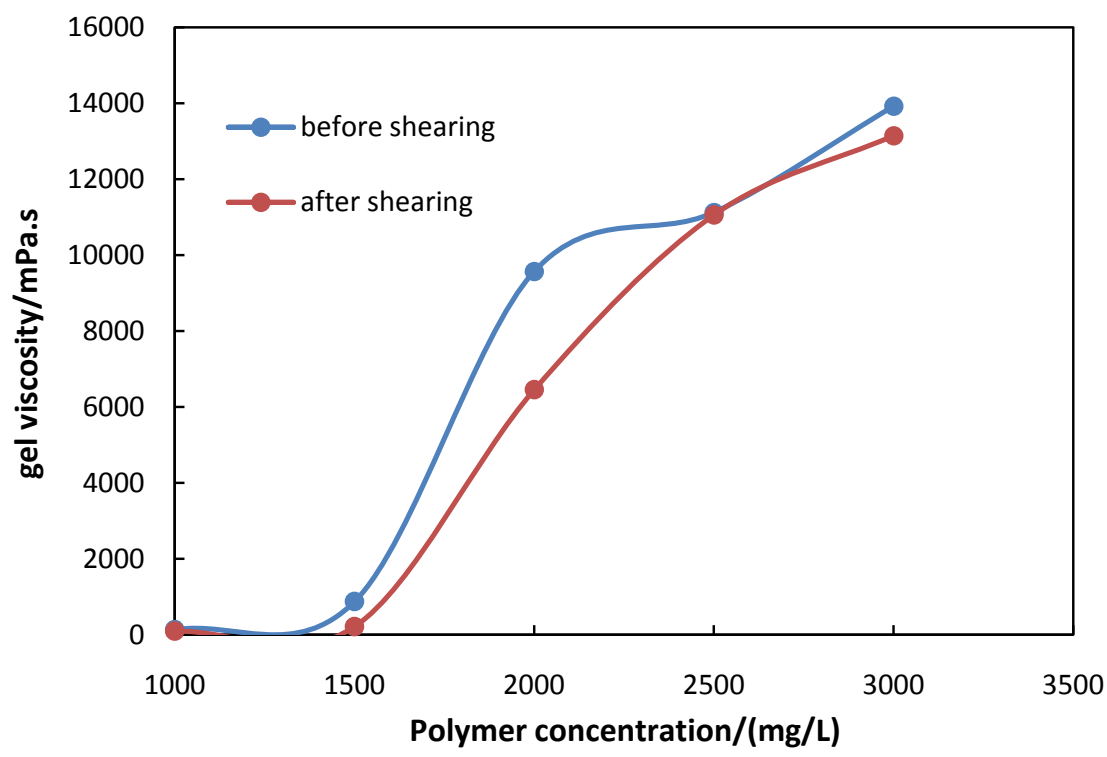

Figure 6. Viscosity curve of gel before and after shearing.

Table 2. Gel aging results.

\begin{tabular}{cc}
\hline polymer concentration $(\mathrm{mg} / \mathrm{L})$ & gel aging results \\
\hline 1000 & No dehydration \\
1500 & No dehydration \\
2000 & No dehydration \\
2500 & No dehydration \\
3000 & Dehydration after 15 days
\end{tabular}

higher than $35 \%$. The drag coefficient and residual resistance coefficient were determined by injecting structural polymer A or gels respectively. The structural 
Table 3. Summary of viscosity concentration relationship of system.

\begin{tabular}{cccc}
\hline system & $\begin{array}{c}\text { viscosity before } \\
\text { shearing/mPa.s }\end{array}$ & $\begin{array}{c}\text { viscosity after } \\
\text { shearing/mPa.s }\end{array}$ & $\begin{array}{c}\text { viscosity retention } \\
\text { rate/\% }\end{array}$ \\
\hline HPAM & $10-201$ & $4.8-134.2$ & $45-66$ \\
structural polymer A & $143-1528$ & $27-1062$ & $19-70$ \\
structural polymer B & $60-144$ & $7-64$ & $12-44$ \\
gel & $135-13,924$ & $97-13,145$ & $72-99$ \\
\hline
\end{tabular}

polymer A concentration is $1250 \mathrm{mg} / \mathrm{L}-3000 \mathrm{mg} / \mathrm{L}$, the results are shown in Table 4, Table 5; gel formula is $1500 \mathrm{mg} / \mathrm{L}$ polymer $+1500 \mathrm{mg} / \mathrm{L}$ phenolic resin cross-linking agent $+1500 \mathrm{mg} / \mathrm{L}$ assistant, and the results are shown in Table 6 .

It can be seen from Table 4 to Table 5 that the resistance coefficient building ability of structural polymer A varies greatly among different flow rates under the permeability model of $10 \mu \mathrm{m}^{2}$. High flow rate of $1.5 \mathrm{ml} / \mathrm{min}$ at low concentration has strong resistance building ability, and low flow rate of $0.5 \mathrm{ml} / \mathrm{min}$ at high concentration has the maximum resistance building ability. When the permeability is greater than $10 \mu \mathrm{m}^{2}$, the influence of each flow rate on resistance coefficient establishment ability is small, from the point of view of resistance building ability, it is considered that polymer is not suitable for formations with permeability above $10 \mu^{2}$. From Table 6 , it is known that when the permeability of the gel system is $10 \mu \mathrm{m}^{2}$ the resistance coefficient of $0.5 \mathrm{~mL} / \mathrm{min}$ is minimum. When the permeability is greater than $10 \mu \mathrm{m}^{2}$, the smaller the flow rate, the greater the drag coefficient and the residual resistance coefficient. The gel system has stronger ability to establish resistance coefficient and residual resistance than structural polymer A flooding system.

\subsection{Gel Flooding System to Improve Recovery Test}

Use the parallel sand filling pipe model to study on gel enhanced oil recovery capability.

Formula: $2500 \mathrm{mg} / \mathrm{L}$ polymer $+0.15 \%$ cocrosslinking agent $+0.15 \%$ cocrosslinking agent 。

Injection volume: 0.3 times of total pore volume 。

The permeability and porosity of high-low permeability model and the change of diversion efficiency and recovery degree in each stage of displacement experiment were recorded in the process of displacement (Table 7).

With the injection pore volume multiplier as the abscissa, the pressure recovery and moisture content were used as the ordinate to draw the parallel recovery factor and water cut curve of weak gel system see in Figure 7.

Taking the multiple of injected pore volume as the abscissa and the diversion rate as the ordinate, the variation trend chart of diversion rate with the change of injection stage in high and low permeability formation is drawn as shown in Figure 8.

The results were as follows 
Table 4. Resistance coefficient and residual resistance coefficient of at $10 \mu \mathrm{m}^{2}$.

\begin{tabular}{rcccc}
\hline concentration $(\mathrm{mg} / \mathrm{L})$ & flow rate $\mathrm{mL} / \mathrm{min}$ & 0.5 & 1.0 & 1.5 \\
\hline \multirow{3}{*}{ resistance coefficient } & 1250 & 50.5 & 78 & 89.21 \\
& 2250 & 85 & 74 & 92 \\
& 3000 & 110 & 70 & 100 \\
residual resistance coefficient & 1250 & 2.72 & 5.77 & 4.89 \\
& 2250 & 7 & 6 & 4.5 \\
& 3000 & 10.56 & 8.81 & 4.48 \\
\hline
\end{tabular}

Table 5. Resistance coefficient and residual resistance coefficient of at $20 \mu \mathrm{m}^{2}$.

\begin{tabular}{ccccc}
\hline & flow rate $\mathrm{mL} / \mathrm{min}$ & 0.5 & 1.0 & 1.5 \\
\hline \multirow{3}{*}{ concentration (mg/L) } & 1250 & 1.72 & 2.2 & 2.7 \\
& 2250 & 8.2 & 5.54 & 7.02 \\
resistance coefficient & 3000 & 13.2 & 13.5 & 14.1 \\
& 1250 & 1.25 & 1.25 & 1.3 \\
& 2250 & 1.25 & 1.3 & 1.35 \\
& 3000 & 1.2 & 1.3 & 1.41 \\
\hline
\end{tabular}

Table 6. Gel resistance coefficient and residual resistance coefficient.

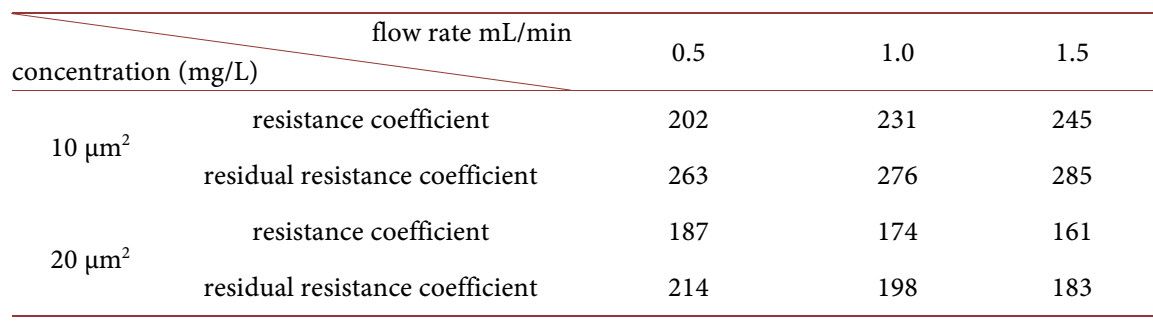

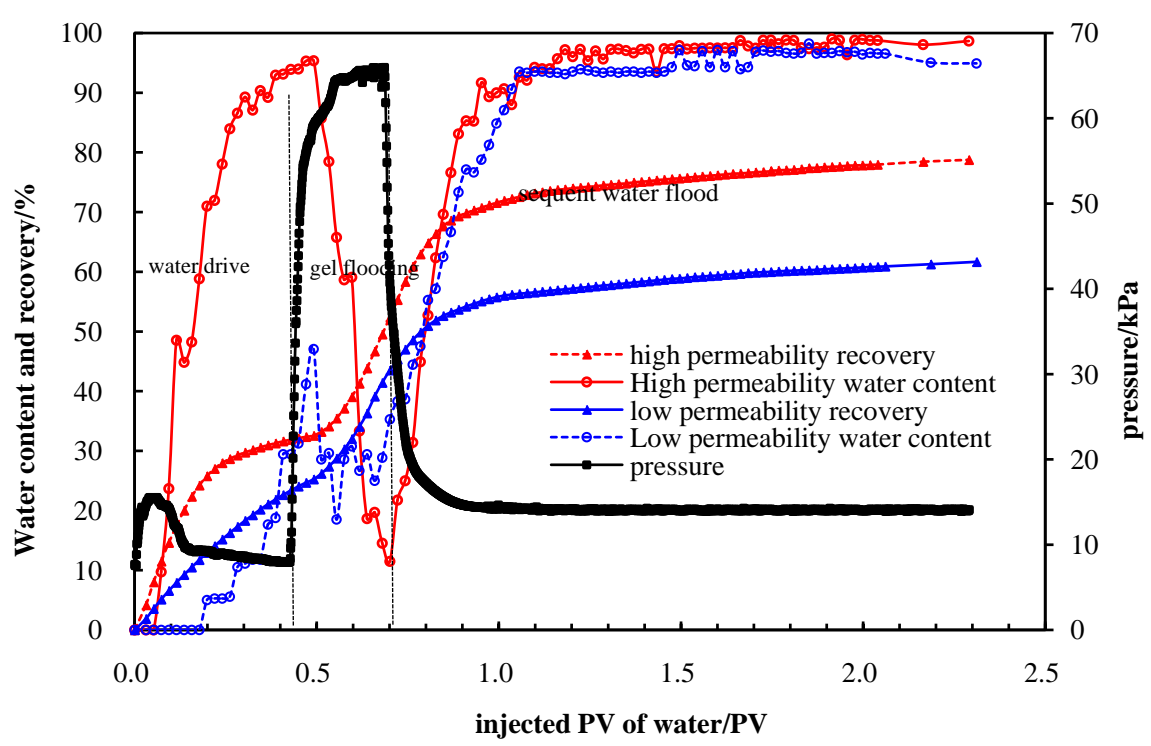

Figure 7. Curve of parallel recovery and water cut. 
Table 7. Improve recovery test.

\begin{tabular}{cccccccc}
\hline sand pack & Permeability $/ \mu \mathrm{m}^{2}$ & porosity/\% & $\begin{array}{c}\text { total pore } \\
\text { volume } / \mathrm{mL}\end{array}$ & $\begin{array}{c}\text { diversion rate in } \\
\text { water drive stage/\% }\end{array}$ & $\begin{array}{c}\text { diversion rate in gel } \\
\text { flooding stage/\% }\end{array}$ & $\begin{array}{c}\text { diversion rate in post } \\
\text { waterflooding stage/\% }\end{array}$ & $\begin{array}{c}\text { recovery } \\
\text { ratio/\% }\end{array}$ \\
\hline low permeability & 10.23 & 37.25 & & 16.35 & 36.67 & 20.88 & 61.66 \\
high permeability & 19.85 & 39.34 & 472 & 83.65 & 60.87 & 79.12 & 78.77 \\
\hline
\end{tabular}

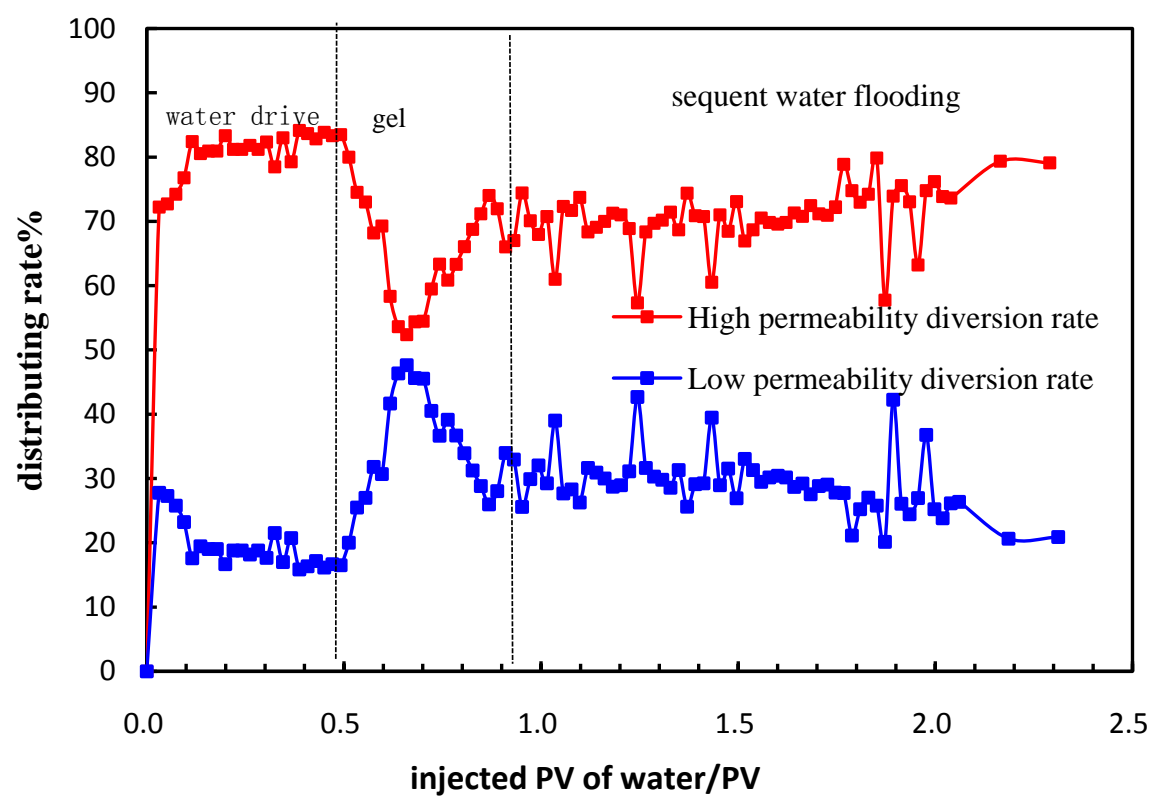

Figure 8. Shunt rate curve.

1) Under the condition of stage difference 2 , the recovery rate of low permeability water drive is $22.63 \%$, and that of high permeability water drive is $31.6 \%$.

2) The recovery of low permeability polymer flooding is $24.37 \%$, and that of high permeability polymer flooding is $29.31 \%$.

3) Under the condition of stage difference 2 , the recovery rate of water flooding after low permeability is $14.66 \%$, and that of water flooding after high permeability is $17.86 \%$.

4) Analysis of the diversion rate curve shows that in the water drive stage, the low permeability basically does not enter the liquid, the diversion rate is low, polymer flooding effectively improves the diversion rate, and finally in the later water drive stage, the diversion rate is effectively improved.

\section{Conclusions}

1) The viscosity of ordinary polymer and structural polymer B is lower before and after shearing. The viscosity of structural polymer A is higher before and after shearing. The higher the concentration, the higher the viscosity retention rate, the highest viscosity of the gel system, and the best shear resistance.

2) Permeability, velocity and polymer concentration all affect the drag coefficient and residual resistance coefficient. From the point of view of resistance establishment ability, it is considered that structural polymer A is not suitable for 
permeability formation above $10 \mu \mathrm{m}^{2}$. Gel system has stronger ability to establish drag coefficient than structural polymer A flooding system, and gel system is more suitable for formations with permeability above $10 \mu \mathrm{m}^{2}$. It is feasible.

\section{Fund Projects}

The research was supported by the major subject "chemical flooding technology of offshore oil field" of 13th 5-year plan (Project No.: 2016ZX05025-003).

\section{Conflicts of Interest}

The authors declare no conflicts of interest regarding the publication of this paper.

\section{References}

[1] Zhang, X.S., Sun, F.J., Xie, X.Q., et al. (2014) Reservoir Technical-Economic Limit of Polymer Floodings and Classification in Bohai Sea. China Offshore Oil and Gas, 26, 51-54.

[2] Li, W.G., Shao, X.J., Kang, Y.Y., et al. (2010) Study on Reservoir Classification System and Method. Lithologic Reservoir, 22, 123-127.

[3] Wu, L. (1995) SY/T 6169-1995 Reservoir Classification.

[4] Guo, T.X. and Su, Y.C. (2013) Current Status and Technical Development Direction in Heavy Oil Reservoir Development in Bohai Oilfields. China Offshore Oil and Gas, 25, 26-30.

[5] Jiang, W. (2006) The Viscous Oil Development Technology in Canada and Considerations of New Technology for Developing Viscous Oil in Bohai Sea, China. China Offshore Oil and Gas, 18, 123-125.

[6] Ji, B.Y. (2012) Progress and Prospects of Enhanced Oil Recovery Technologies at Home and Abroad. Oil \& Gas Geology, 33, 111-117.

[7] Leng, J., Pan, Y., Li, D.S., et al. (2014) Application of Chemical Flooding Technology. Contemporary Chemical Industry, 43, 1495-1497.

[8] Tu, G.Y., Wei, Q.T., Chen, Y.Q., et al. (2018) Optimization Study on Polymer Injection Mode in S Block of Daqing Oilfield. Contemporary Chemical Industry, 47. 236-239.

[9] Han. L.J. (2004) Study on Structural Polymer A in Oil and Gas Development. Doctoral Dissertation, Southwest Petroleum University, Chengdu.

[10] Zhao, J., Zhang, J., Yang, G., et al. (2016) Oil Displacement Performance and Viscosity-Reducing Effect of Structural Polymer B with Amphiphilic Polymer. Oilfield Chemistry, 33, 715-719. 